\title{
International Workshop on Learning by Modelling in Science Education
}

\author{
Bert Bredeweg ${ }^{1, *}$ and Paulo Salles ${ }^{2, *}$ \\ ${ }^{1}$ University of Amsterdam, Informatics Institute, Amsterdam, Netherlands \\ b. bredeweg@uva.n1 \\ ${ }^{2}$ University of Brasília, Institute of Biological Sciences, Brazil \\ psalles@unb.br
}

Summary. Modelling is nowadays a well-established methodology in the sciences, supporting the inquiry and understanding of complex phenomena and systems in the natural, social and artificial worlds. Hence its strong potential as pedagogical approach fostering students' learning of scientific concepts and skills, in a systemic perspective. Modelling helps learners to express and externalise their thinking; visualise and test components of their theories; and make materials more interesting. Modelling and simulation in education can thus make a significant contribution to improve science learning.

Different kinds of modelling environments have been created. Environments such as NetLogo, Stella and Model-It are some examples that offer innovative environments in which students can construct their own models and simulations to solve problems of interest to them. More recent advancements have delivered interactive diagrammatic representations based on Qualitative Reasoning, e.g. Betty's Brain, Vmodel, and DynaLearn. Environments such as these allow learners to view the invisible and examine complexity in ways that were previously impossible.

Learning by Modelling (LbM) may contribute to students' learning of scientific concepts and skills. LbM tools implemented as constructivist environments have the potential to support the learners' gradual construction of knowledge and mastery of skills, and to increase their motivation to explore scientific phenomena. Moreover, LbM implies the acquisition of skills and perspectives that may become in the longterm powerful intellectual tools for addressing systemic phenomena in new situations and contexts. Hence its status as promising approach for science education.

Computational modelling can serve two roles in approaching these issues. First, creating and evaluating models can serve to help learners deepen their scientific knowledge and skills, and become aware of the joy of understanding scientific topics. Second, computational modelling is an excellent example of daily professional work in scientific laboratories, in which models are used to create understanding of deep and complex scientific problems.

Programme Committee: Rachel Or-Bach (Academic College of Emek Yezreel, Israel), Gautam Biswas (Vanderbilt Univ., USA), Wouter van Joolingen (Univ. of Twente, The Netherlands), Jochem Liem (Univ. of Amsterdam, The Netherlands), David Mioduser (Tel Aviv Univ., Israel), Julie-Ann Sime (Lancaster Univ., UK), Elliot Soloway (Univ. of Michigan Ann Arbor, USA), Andrew Ravenscroft (London Metropolitan Univ., UK), Michael Timms (WestEd, USA), Xiu-Tian Yan (Univ. of Strathclyde, UK).

* Workshop Co-Chairs. 